\title{
Visualization of the geophysical settings in the Philippine Sea margins by means of GMT and ISC data
}

\author{
Polina Lemenkova \\ Ocean University of China, College of Marine Geo-sciences, \\ 238 Songling Rd, Laoshan, 266100, Qingdao, Shandong, China; \\ pauline.lemenkova@gmail.com
}

Received: 22 February 2020; Revised: 9 March 2020; Accepted: 12 March 2020; Published online: 25 March 2020

\begin{abstract}
The presented research aimed to perform geophysical modelling (gravity and geoid) and to evaluate the spatio-temporal variation of the marine geological data (distribution and depth of earthquakes) using combination of the Generic Mapping Tools (GMT) and available sources from the International Seismological Centre (ISC-EHB) that produce data on earthquakes as part of seismic survey and regional research projects. The target study area is a Philippine Sea basin (PSB) with two focused marginal areas: Philippine Trench and Mariana Trench, two hadal trenches located in the places of the tectonic plates subduction. Marine free-air gravity anomaly in the PSP shows higher values ( $>80 \mathrm{mGal}$ ) of the gravity fields structure at the volcanic areas and Philippine archipelago. Current study presented comparative geophysical analysis, and mapping free-air gravity and geoid in the Philippine Sea basin area. As a result of this study, the average level of earthquakes located in the Philippine Trench and Mariana Trench areas were compared, and those located in the Philippine archipelago are determined to be in the souther-western part (area of west Mindanao, south-west Visayas islands), while Luzon Islands shown shallower located earthquakes. The results on the Mariana Trench segment shown shallower located earthquakes compared of the other marginal regions of the Philippine Sea Basin. Current paper contributes to the studies on natural hazards through visualization and analysis of the earthquakes activities (occurrence and magnitude intensity), due to increasing interest to the problems of seismicity in the Pacific Ocean, which may have environmental effects causing harmful consequences and possible risks for coastal population of the Philippine islands through aftershocks and tsunami.
\end{abstract}

Key words: GMT, cartography, shell scripting, geoid, free-air gravity, geophysics, visualization, earthquake

https://doi.org/10.47246/CEJGSD.2020.2.1.1

\section{| Full text |}

